\title{
Dementia and COVID-19: A Case Report and Literature Review on Pain Management
}

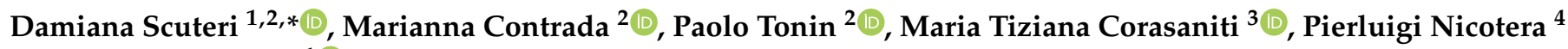 \\ and Giacinto Bagetta ${ }^{1}$ (B)
}

check for

updates

Citation: Scuteri, D.; Contrada, M.;

Tonin, P.; Corasaniti, M.T.; Nicotera,

P.; Bagetta, G. Dementia and

COVID-19: A Case Report and

Literature Review on Pain

Management. Pharmaceuticals 2022,

15, 199. https://doi.org/10.3390/

ph15020199

Academic Editors: Giulia Sita and

Antoni Camins Espuny

Received: 14 January 2022

Accepted: 3 February 2022

Published: 4 February 2022

Publisher's Note: MDPI stays neutral with regard to jurisdictional claims in published maps and institutional affiliations.

Copyright: (C) 2022 by the authors. Licensee MDPI, Basel, Switzerland. This article is an open access article distributed under the terms and conditions of the Creative Commons Attribution (CC BY) license (https:// creativecommons.org/licenses/by/ $4.0 /)$.
1 Pharmacotechnology Documentation and Transfer Unit, Preclinical and Translational Pharmacology, Department of Pharmacy, Health and Nutritional Sciences, University of Calabria, 87036 Rende, Italy; g.bagetta@unical.it

2 Regional Center for Serious Brain Injuries, S. Anna Institute, 88900 Crotone, Italy; mariannacontrada@gmail.com (M.C.); patonin18@gmail.com (P.T.)

3 Department of Health Sciences, University "Magna Graecia” of Catanzaro, 88100 Catanzaro, Italy; mtcorasa@unicz.it

4 German Center for Neurodegenerative Diseases (DZNE), 53127 Bonn, Germany; pierluigi.nicotera@dzne.de

* Correspondence: damiana.scuteri@unical.it; Tel.: +39-0984/493462

\begin{abstract}
The coronavirus disease 2019 (COVID-19) pandemic imposes an unprecedented lifestyle, dominated by social isolation. In this frame, the population to pay the highest price is represented by demented patients. This group faces the highest risk of mortality, in case of severe acute respiratory syndrome coronavirus (SARS-CoV-2) infection, and they experience rapid cognitive deterioration, due to lockdown measures that prevent their disease monitoring. This complex landscape mirrors an enhancement of neuropsychiatric symptoms (NPSs), with agitation, delirium and reduced motor performances, particularly in non-communicative patients. Due to the consistent link between agitation and pain in these patients, the use of antipsychotics, increasing the risk of death during COVID-19, can be avoided or reduced through an adequate pain treatment. The most suitable pain assessment scale, also feasible for e-health implementation, is the Mobilization-Observation-Behaviour-IntensityDementia (MOBID-2) pain scale, currently under validation in the Italian real-world context. Here, we report the case of an 85-year-old woman suffering from mild cognitive impairment, subjected to off-label treatment with atypical antipsychotics, in the context of undertreated pain, who died during the pandemic from an extensive brain hemorrhage. This underscores the need for appropriate assessment and treatment of pain in demented patients.
\end{abstract}

Keywords: COVID-19; dementia; pain assessment; NPSs; MOBID-2; tele-neurorehabilitation

\section{Introduction}

The outbreak of coronavirus disease 2019 (COVID-19) imposes novel life rules, dominated by quarantine, social distancing (up to lockdown) and the use of personal protective equipment. The distance and the assistance by mask-wearing, seemingly faceless caregivers, worsen the cognitive and behavioral consciousness and, consequently, affect the most fragile population, i.e., the uncommunicative elderly, suffering from moderate to severe dementia. Currently, some 55 million people suffer from dementia, with $75 \%$ demented people (some 41 million) being undiagnosed [1], and this number is estimated to reach 78 million by 2030 and 139 million by 2050. Patients affected by Alzheimer's disease $(\mathrm{AD})$ have contracted the infection more frequently and present increased risk of death $[2,3]$. In fact, $80 \%$ of COVID-19 deaths are in nursing homes, since living in care facilities increases the risk of mortality [4]; accordingly, more than a third of mortality can be represented by AD patients [5]. The analysis of the primary health records of 13,338 UK individuals shows that a pre-existing diagnosis of AD is associated with the highest risk of COVID-19 and mortality [6]. People suffering from dementia present an increased risk 
of contracting the infection, due to severe acute respiratory syndrome coronavirus (SARSCoV-2) and develop more serious sequelae, induced both by severe COVID-19 and by isolation measures [7]. In fact, both conditions can aggravate neuropsychiatric symptoms (NPSs) [8], confusion and agitation [7], because of the interaction with pharmacological treatments [9], and COVID-19 can present as delirium and worsened agitation in these patients $[10,11]$. However, some disorders, such as Wilson's disease, were surprisingly not affected by COVID-19 pandemic [12]. Agitation can represent a form of help-seeking in response to unrelieved pain $[13,14]$, one of the triggers commonly responsible for agitation that can be effectively managed through analgesics [15]. In fact, the chronic pain treatment of AD patients is limited in real-world settings and related with increased and harmful use of antipsychotics and antidepressants [16-18]. The severity of pain is associated with NPSs and antipsychotics prescriptions [19] and a Delphi consensus proves the priority of analgesia in the management of NPSs [20]. Therefore, an integrated pain management [21], allowing appropriate pain treatment, can reduce the use of antipsychotics for NPSs treatment [22,23], decreasing cardiocerebrovascular events that represent a mortality risk factor for COVID-19 [24]. Almost two years after the onset of this dramatic pandemic, and although lots of documents, produced by several countries, to provide instructions for adequate and supportive care for people with dementia, specific guidelines for pain assessment and management for patients with dementia, also in the circumstance of forced social isolation, are currently unavailable. The evidence gathered prompts the presentation of a case report, pointing at the urgent need for accurate pain assessment and treatment in the fragile population of the elderly, suffering from mild cognitive decline and dementia, with impaired communication capabilities.

\subsection{Neurobiological Common Ground of COVID-19 and Dementia}

The COVID-19 pandemic raises the most serious consequences in the fragile population of the elderly, finding them often affected by cognitive impairment from dementia, named Alzheimer's disease, and related dementias (ADRD) [25]. The latter patients display a higher risk to be infected by SARS-CoV-2 because of the difficulty for them to remember and put into practice the preventative safeguard measures, adopted worldwide, and also due to their dependence on caregivers and assistance in nursing homes, often with sustained virus circulation [25]. Social restriction enhances the already occurring isolation of these patients and necessary effective telehealth programs, to impede the complete loss of motor abilities, are still not adopted in many real-world settings [26]. Incidentally, COVID-19 has been demonstrated to induce neurological symptoms attributable to the central nervous system, e.g., impaired consciousness, but also agitation, confusion and corticospinal tract signs [27]. Cognitive deterioration can be due to the development of acute respiratory distress syndrome (ARDS), which occurs in 14.8\% cases [28]. As for AD, anosmia is a frequent symptom and NPSs, delirium and a change in mental health can be the presentation of symptoms of the infection [29]. Furthermore, COVID-19 is suggested to be responsible for long-term neurological sequelae and dementia. In fact, SARS-CoV-2 receptor angiotensin-converting enzyme-2 (ACE-2) is expressed by neuronal and glial cells [30]. Using 18F-fluorodeoxyglucose (18F-FDG) positron emission tomography/computerized tomography (PET/CT) brain imaging, in the course of acute encephalopathy, patients displaying cognitive dysfunction and frontal behavioral changes present hypometabolism of the prefrontal cortex, predominant on the right side, bilateral insula, anterior cingulate and caudate nucleus, associated with increased blood (and in some cases cerebrospinal fluid) levels of interleukin-6 (IL-6) [31]. The nucleotide-binding domain and leucine-rich repeat (NLR) pyrin domain-containing 3 (NLRP3) inflammasome, known to be implicated in $\mathrm{AD}[32,33]$, is involved in systemic inflammation, induced by SARS-CoV-2 infection $[27,34]$. This is demonstrated by the evidence of vascular and aberrant immune reaction-related factors [35]. Furthermore, after contracting COVID-19, the risk of being hospitalized is doubled in patients homozygous for $\mathrm{APOE} \varepsilon 4$, a known risk factor for $\mathrm{AD}$ [36], that results in a predictor of doubled risk of severe infection and of quadruple risk of mortality [37-39]. The 
so-called, COVID-19-induced "brain fog" can be long-lasting, accelerating cognitive decline in AD patients, and this may be supported by the western blotting evidence of increased levels of ACE-2 in AD patients' hippocampal tissue [40]. Moreover, brain hypoperfusion can accelerate amyloid- $\beta(A \beta)$ and tau accumulation, together with the transactivation response DNA-binding protein of $43 \mathrm{kDa}$ (TDP-43) pathology [41].

\subsection{Observational Pain Assessment}

The evidence that patients suffering from dementia develop an aberrant transmission and modulation of pain [42], together with age-related comorbidities associated with pain, accounts for the presence of chronic pain states in 50\% demented people [43], reaching $80 \%$ in long-term care facilities [44], often under-detected [45,46]. Pain assessment is difficult in patients suffering from severe dementia due to their reduced communication skills. Therefore, behavioral and physiological indicators of pain, in particular pain noises, facial expressions and defensive behaviours, are fundamental to diagnose and unravel non-selfreported pain. Under-treated pain is tightly connected to NPSs, causing agitation, which is managed through neuroleptics, doubling the risk of death for cardiocerebrovascular accidents in the elderly [47], representing a mortality cause during COVID-19 infection; an appropriate diagnosis and therapy for pain is fundamental to reduce the risk of death [24]. A retrospective case-control study provides evidence for increased mortality risk in patients, after initiation of a treatment with an antipsychotic (i.e. haloperidol, olanzapine, quetiapine, and risperidone) [48].

\section{Case Report}

Here, we present the case of an 85-year-old woman, with mild cognitive impairment, who died during the pandemic, due to the lack of accurate pain management in the real-world setting of a Southern Italian health district. The neurologic visit led to the prescription of sertraline and haloperidol, the latter administered during acute attacks. After a fall, causing persistent leg joint pain, the patient was sent for geriatrician evaluation, for worsened cognitive dysfunction and unmanageable agitation. The pain assessment and treatment was delayed because of the health emergency and the agitation was considered so severe as to require institutionalization and off-label treatment with the antipsychotic, quetiapine. Within the first ten days after admittance to the nursing home, the mild cognitive impairment progressed into uncommunicative, rapid cognitive decline, accompanied by intractable agitation and delirium, leading to high dosage benzodiazepines that contributed to exacerbating the confusion. One week later, the patient was not able to recognize her relatives and died from an extensive brain hemorrhage. In fact, she was moved to the emergency room of the referred hospital for suspected stroke, but imaging analysis proved it was a brain hemorrhage that led to her death the following day in the hospital. The patient presented good hematochemistry parameters and she had no other cardiovascular risk factors, apart from treatment with antidepressants, previously. The patient had suffered a previous stroke, earlier than ten years and presented senile atrophy, demonstrated by neuroimaging. Unfortunately, this case confirms that delirium may be associated with an increased risk of hospitalization and mortality [49]. Particularly remarkable, is that the cognitive and neuropsychiatric status precipitated due to the lack of adequate pain assessment and treatment.

\section{Discussion}

\subsection{Pain Scales and E-health}

Pain assessment is fundamental to improve the quality of life of patients suffering from dementia and to decrease their mortality risk during the pandemic. One of the barriers most difficult to overcome in dementia is represented by the loss of communication skills that these patients experience, preventing them from pain self-report. Furthermore, the social isolation contributes to the worsening of cognitive impairment, and the delaying of non-urgent medical examinations causes the neglection of the assessment, monitoring 
and treatment of dementia [50] and consequently pain and NPSs. Furthermore, the lack of care exacerbates the reduction in motor function of cognitively impaired patients, requiring rehabilitation. Therefore, observational pain scales, feasible for telehealth administration, are needed during the pandemic. In fact, tele-neurorehabilitation has proven not inferior to standard treatment [51]. Among the existing internationally validated observational pain scales for uncommunicative patients affected by severe dementia, the MobilizationObservation-Behaviour-Intensity-Dementia (MOBID-2) pain scale is unique of its kind, being developed to take into account the common overlapping of musculoskeletal and visceral pain [52], through behavioral indicators of pain, i.e., pain noises, facial expressions and defensive behaviours. The first part of MOBID-2 was developed for the assessment of musculoskeletal pain, also unraveling hidden pain conditions, through five guided movements of different body parts [53]. The second part is developed for the assessment of pain from internal organs, head and skin [53]. The international validation of this tool in severe dementia highlights its remarkable psychometric properties, as good face and construct $($ Part1 rho $=0.82 ;$ Part2 rho $=0.61)$ validity and very good inter-rater $(\operatorname{ICC}(1,1)$ $0.80-0.94)$ and test-retest (ICC $(1,1) 0.60-0.94)$ reliability (Table 1$)$ for pain intensity [53]. This scale is suitable for virtual assessment of pain and its Italian version is currently under validation in the Italian context.

Table 1. Clinimetric properties of the Mobilization-Observation-Behaviour-Intensity-Dementia (MOBID-2) pain scale.

\begin{tabular}{|c|c|c|c|c|}
\hline $\begin{array}{l}\text { Description of the } \\
\text { Pain Assessment Tool }\end{array}$ & Structure of the Scale & Time Efficiency & $\begin{array}{c}\text { Healthcare } \\
\text { Operator in } \\
\text { Charge }\end{array}$ & $\begin{array}{l}\text { Psychometric Properties: } \\
\text { Validity and Reliability }\end{array}$ \\
\hline $\begin{array}{l}\text { Observational scale for } \\
\text { non communicative } \\
\text { patients affected by } \\
\text { severe dementia }\end{array}$ & $\begin{array}{l}\text { It is composed by } 10 \text { items, } \\
5 \text { per each part. The part } 1 \text { is } \\
\text { conceived for the assessment } \\
\text { of musculoskeletal pain } \\
\text { through the guided execution } \\
\text { of } 5 \text { active movements to } \\
\text { unravel also hidden pain } \\
\text { conditions. In the part } 2 \text { pain } \\
\text { from head, skin and internal } \\
\text { organs is assessed. }\end{array}$ & $\begin{array}{l}\text { The mean time } \\
\text { needed for } \\
\text { execution is } \\
4.37 \mathrm{~min} \text {. }\end{array}$ & $\begin{array}{l}\text { Nurses receiving } \\
\text { a } 2 \text { h educational } \\
\text { session. }\end{array}$ & $\begin{array}{c}\text { Inter-rater and test-retest } \\
\text { reliability for pain intensity: } \\
\text { ICC } 0.80-0.94 \text { and } 0.60-0.94 \text {. } \\
\text { Correlation with physicians } \\
\text { numerical rating scale (NRS) } \\
\text { scoring and defined } \\
\text { pain variables } \\
\quad(\text { rho }=0.41-0.64)[53] .\end{array}$ \\
\hline
\end{tabular}

\subsection{The Possible Role for E-health}

In the initial phases, Italy was overwhelmed by the pandemic, with $11.9 \%$ of deceased COVID-19 positive patients affected by dementia [54], afflicting 900-1000 per 100,000 inhabitants [55]. Particularly worthy of note is that demented patients are more at risk to receive inadequate treatments during the health emergency [54]. Unfortunately, the latter observation finds confirmation in pain management during the pandemic. The overlapping of several pathogenetic pathways, between AD and COVID-19, accounts for their synergistic action in cognitive deterioration, enhancing the frailty of patients suffering from dementia in this scenario. Lockdowns and social distancing worsen the cognitive and motor performances of these patients and delay their monitoring, making it necessary to provide severely demented patients with pain assessment and neurorehabilitation by means of telemedicine. An excellent example to follow is represented by the development of intelligent assistive systems, to obtain high-quality behavior data from real-world environments [56]. Here, we report the case of an 85-year-old woman, suffering from mild cognitive impairment, who died from an extensive brain hemorrhage during the last period of the health emergency, because of the lack of accurate pain management, leading to institutionalization and off-label treatment with atypical antipsychotics, known to double the risk of death of these fragile patients. Although the study limitation that an actual causal relationship cannot be established, this case report supports the need for novel 
efficient strategies, including telemedicine, to afford appropriate assessment and treatment of pain in demented patients during the pandemic.

\section{Conclusions: Novel Pharmacological Perspectives}

The tight link between COVID-19 and dementia highlights the need for greater attention to pain assessment and treatment during the pandemic. Dementia can be exacerbated by acute respiratory distress syndrome, the neurological sequelae of the infection and, also, the social isolation measures to prevent contagion. In particular, the highest mortality for COVID-19 is registered among patients suffering from dementia that are often diagnosed with the infection because of a worsening of agitation, one of the most challenging behavioural and psychological symptoms of dementia (BPSD), and the occurrence of delirium. Agitation is often a form of help-seeking for underdiagnosed and, consequently, unrelieved pain, in non-communicative demented patients. The assessment and management of chronic pain, often experienced by patients affected by dementia due to age-related comorbidities, is made even more difficult during the pandemic because of lockdowns and delayed specialistic examinations. This complex scenario leads to an increased rate of inappropriate prescriptions of antipsychotics to manage agitation due to undertreated pain, doubling the risk of death from stroke, which can be a complication of COVID-19, in the fragile population of demented patients. Therefore, it is fundamental to avoid the unnecessary and harmful use of antipsychotics and antidepressants; on the other hand, the novel rapid-acting antidepressants are worthy of investigation [57]. This paves scenario the way for the use of essential oils, also feasible in telemedicine healthcare; among these, the essential oil of bergamot is the most suitable for its proven analgesic [58] and anxiolyticlike properties [59]. Moreover, it has been developed in the form of a cream, carrying a nanotechnological delivery device to preserve the oil and allow double-masking [60] of the ongoing clinical trial, for proof of concept in severe dementia (NCT04321889) [61]. This can allow adequate pain management, avoiding or reducing, also, the use of potent analgesics, such as opioids, endowed with serious side effects and not properly tested for efficacy and safety in fragile populations, including dementia-affected and post-stroke patients [62].

Author Contributions: Conceptualization, D.S. and G.B.; data curation, D.S., M.C., P.T., M.T.C., P.N., G.B. All authors have read and agreed to the published version of the manuscript.

Funding: This research received external funding in the frame of "Prima Vera Azione-(PrimaVerAzione)" prot. INVITALIA 37600 del 21/02/2021, PoC entitled "Analgesic efficacy of bergamot without furocumar ins loaded in a nanotechnological system to release the essential oil of bergamot for clinical translation in the treatment of agitation in patients over 65 affected by severe dementia".

Institutional Review Board Statement: Not applicable.

Informed Consent Statement: Written informed consent was obtained from the patient's sons to publish this paper.

Data Availability Statement: Data is contained within the article.

Acknowledgments: D.S. is a researcher in the frame of the project supported by the Italian Ministry of Health: NET-2016-02361805 (WP 5).

Conflicts of Interest: The authors declare no conflict of interest.

\section{References}

1. Gauthier, S.; Rosa-Neto, P.; Morais, J.A.; Webster, C. World Alzheimer Report 2021: Journey through the diagnosis of dementia. Lond. Engl. Alzheimer's Dis. Int. 2021.

2. Liu, N.; Sun, J.; Wang, X.; Zhao, M.; Huang, Q.; Li, H. The Impact of Dementia on the Clinical Outcome of COVID-19: A Systematic Review and Meta-Analysis. J. Alzheimer's Dis. JAD 2020, 78, 1775-1782. [CrossRef] [PubMed]

3. Burns, A.; Howard, R. COVID-19 and dementia: A deadly combination. Int. J. Geriatr. Psychiatry 2021, 36, 1120-1121. [CrossRef] [PubMed]

4. Matias-Guiu, J.A.; Pytel, V.; Matías-Guiu, J. Death Rate Due to COVID-19 in Alzheimer's Disease and Frontotemporal Dementia J. Alzheimer's Dis. JAD 2020, 78, 537-541. [CrossRef] 
5. Perry, G. Alzheimer's Disease Patients in the Crosshairs of COVID-19. J. Alzheimer's Dis. JAD 2020, 76, 1. [CrossRef]

6. Yu, Y.; Travaglio, M.; Popovic, R.; Leal, N.S.; Martins, L.M. Alzheimer's and Parkinson's Diseases Predict Different COVID-19 Outcomes: A UK Biobank Study. Geriatrics 2021, 6, 10. [CrossRef]

7. Numbers, K.; Brodaty, H. The effects of the COVID-19 pandemic on people with dementia. Nat. Rev. Neurol. 2021, 17, 69-70. [CrossRef]

8. Velayudhan, L.; Aarsland, D.; Ballard, C. Psychiatric and neuropsychiatric syndromes and COVID-19. Lancet. Psychiatry 2020, 7, 663-664. [CrossRef]

9. Jansen van Vuren, E.; Steyn, S.F.; Brink, C.B.; Möller, M.; Viljoen, F.P.; Harvey, B.H. The neuropsychiatric manifestations of COVID-19: Interactions with psychiatric illness and pharmacological treatment. Biomed. Pharmacother. = Biomed. Pharmacother. 2021, 135, 111200. [CrossRef]

10. Benussi, A.; Pilotto, A.; Premi, E.; Libri, I.; Giunta, M.; Agosti, C.; Alberici, A.; Baldelli, E.; Benini, M.; Bonacina, S.; et al. Clinical characteristics and outcomes of inpatients with neurologic disease and COVID-19 in Brescia, Lombardy, Italy. Neurology 2020, 95, e910. [CrossRef]

11. McLoughlin, B.C.; Miles, A.; Webb, T.E.; Knopp, P.; Eyres, C.; Fabbri, A.; Humphries, F.; Davis, D. Functional and cognitive outcomes after COVID-19 delirium. Eur. Geriatr. Med. 2020, 11, 857-862. [CrossRef] [PubMed]

12. Lanza, G.; Godani, M.; Ferri, R.; Raggi, A. Impact of COVID-19 pandemic on the neuropsychiatric status of Wilson's disease. World J. Gastroenterol. 2021, 27, 6733-6736. [CrossRef] [PubMed]

13. Sampson, E.L.; White, N.; Lord, K.; Leurent, B.; Vickerstaff, V.; Scott, S.; Jones, L. Pain, agitation, and behavioural problems in people with dementia admitted to general hospital wards: A longitudinal cohort study. Pain 2015, 156. [CrossRef] [PubMed]

14. Atee, M.; Morris, T.; Macfarlane, S.; Cunningham, C. Pain in Dementia: Prevalence and Association With Neuropsychiatric Behaviors. J. Pain Symptom Manag. 2021, 61, 1215-1226. [CrossRef]

15. Husebo, B.S.; Ballard, C.; Sandvik, R.; Nilsen, O.B.; Aarsland, D. Efficacy of treating pain to reduce behavioural disturbances in residents of nursing homes with dementia: Cluster randomised clinical trial. Bmj 2011, 343, d4065. [CrossRef] [PubMed]

16. Scuteri, D.; Piro, B.; Morrone, L.A.; Corasaniti, M.T.; Vulnera, M.; Bagetta, G. The need for better access to pain treatment: Learning from drug consumption trends in the USA. Funct. Neurol. 2017, 22, 229-230. [CrossRef]

17. Scuteri, D.; Garreffa, M.R.; Esposito, S.; Bagetta, G.; Naturale, M.D.; Corasaniti, M.T. Evidence for accuracy of pain assessment and painkillers utilization in neuropsychiatric symptoms of dementia in Calabria region, Italy. Neural Regen. Res. 2018, 13, 1619-1621. [CrossRef]

18. Scuteri, D.; Vulnera, M.; Piro, B.; Bossio, R.B.; Morrone, L.A.; Sandrini, G.; Tamburin, S.; Tonin, P.; Bagetta, G.; Corasaniti, M.T. Pattern of treatment of behavioural and psychological symptoms of dementia and pain: Evidence on pharmacoutilization from a large real-world sample and from a centre for cognitive disturbances and dementia. Eur. J. Clin. Pharmacol. 2021, 77, 241-249. [CrossRef]

19. Rajkumar, A.P.; Ballard, C.; Fossey, J.; Orrell, M.; Moniz-Cook, E.; Woods, R.T.; Murray, J.; Whitaker, R.; Stafford, J.; Knapp, M.; et al. Epidemiology of Pain in People With Dementia Living in Care Homes: Longitudinal Course, Prevalence, and Treatment Implications. J. Am. Med. Dir. Assoc. 2017, 18, 453.e451-453.e456. [CrossRef]

20. Kales, H.C.; Lyketsos, C.G.; Miller, E.M.; Ballard, C. Management of behavioral and psychological symptoms in people with Alzheimer's disease: An international Delphi consensus. Int. Psychogeriatr. 2019, 31, 83-90. [CrossRef]

21. Corbett, A.; Husebo, B.S.; Achterberg, W.P.; Aarsland, D.; Erdal, A.; Flo, E. The importance of pain management in older people with dementia. Br. Med. Bull. 2014, 111, 139-148. [CrossRef]

22. Ballard, C.G.; Gauthier, S.; Cummings, J.L.; Brodaty, H.; Grossberg, G.T.; Robert, P.; Lyketsos, C.G. Management of agitation and aggression associated with Alzheimer disease. Nat. Rev. Neurol. 2009, 5, 245-255. [CrossRef]

23. Corbett, A.; Burns, A.; Ballard, C. Don't use antipsychotics routinely to treat agitation and aggression in people with dementia. BMJ 2014, 349, g6420. [CrossRef]

24. Scuteri, D.; Matamala-Gomez, M.; Bottiroli, S.; Corasaniti, M.T.; De Icco, R.; Bagetta, G.; Tonin, P. Pain Assessment and Treatment in Dementia at the Time of Coronavirus Disease COVID-19. Front. Neurol. 2020, 11, 890. [CrossRef]

25. Wang, H.; Li, T.; Barbarino, P.; Gauthier, S.; Brodaty, H.; Molinuevo, J.L.; Xie, H.; Sun, Y.; Yu, E.; Tang, Y.; et al. Dementia care during COVID-19. Lancet 2020, 395, 1190-1191. [CrossRef]

26. Ortelli, P.; Ferrazzoli, D.; Versace, V.; Saltuari, L.; Sebastianelli, L. The need for psychological, caregiver-centered intervention in the time of COVID-19. Alzheimer's Dement. Transl. Res. Clin. Interv. 2021, 7, e12166. [CrossRef]

27. Heneka, M.T.; Golenbock, D.; Latz, E.; Morgan, D.; Brown, R. Immediate and long-term consequences of COVID-19 infections for the development of neurological disease. Alzheimer's Res. Ther. 2020, 12, 69. [CrossRef]

28. Rodriguez-Morales, A.J.; Cardona-Ospina, J.A.; Gutiérrez-Ocampo, E.; Villamizar-Peña, R.; Holguin-Rivera, Y.; Escalera-Antezana, J.P.; Alvarado-Arnez, L.E.; Bonilla-Aldana, D.K.; Franco-Paredes, C.; Henao-Martinez, A.F.; et al. Clinical, laboratory and imaging features of COVID-19: A systematic review and meta-analysis. Travel Med. Infect. Dis. 2020, 34, 101623. [CrossRef]

29. Beach, S.R.; Praschan, N.C.; Hogan, C.; Dotson, S.; Merideth, F.; Kontos, N.; Fricchione, G.L.; Smith, F.A. Delirium in COVID-19: A case series and exploration of potential mechanisms for central nervous system involvement. Gen. Hosp. Psychiatry 2020, 65, 47-53. [CrossRef]

30. Zhou, Z.; Kang, H.; Li, S.; Zhao, X. Understanding the neurotropic characteristics of SARS-CoV-2: From neurological manifestations of COVID-19 to potential neurotropic mechanisms. J. Neurol. 2020, 267, 2179-2184. [CrossRef] [PubMed] 
31. Kas, A.; Soret, M.; Pyatigoskaya, N.; Habert, M.-O.; Hesters, A.; Le Guennec, L.; Paccoud, O.; Bombois, S.; Delorme, C.; on the behalf of CoCo-Neurosciences Study Group; et al. The cerebral network of COVID-19-related encephalopathy: A longitudinal voxel-based 18F-FDG-PET study. Eur. J. Nucl. Med. Mol. Imaging 2021, 48, 2543-2557. [CrossRef]

32. Tejera, D.; Mercan, D.; Sanchez-Caro, J.M.; Hanan, M.; Greenberg, D.; Soreq, H.; Latz, E.; Golenbock, D.; Heneka, M.T. Systemic inflammation impairs microglial A $\beta$ clearance through NLRP3 inflammasome. EMBO J. 2019, 38, e101064. [CrossRef]

33. White, C.S.; Lawrence, C.B.; Brough, D.; Rivers-Auty, J. Inflammasomes as therapeutic targets for Alzheimer's disease. Brain Pathol. 2017, 27, 223-234. [CrossRef] [PubMed]

34. Vora, S.M.; Lieberman, J.; Wu, H. Inflammasome activation at the crux of severe COVID-19. Nat. Rev. Immunol. 2021, 21, 694-703. [CrossRef] [PubMed]

35. Fisicaro, F.; Di Napoli, M.; Liberto, A.; Fanella, M.; Di Stasio, F.; Pennisi, M.; Bella, R.; Lanza, G.; Mansueto, G. Neurological Sequelae in Patients with COVID-19: A Histopathological Perspective. Int J Env. Res Public Health 2021, 18, 1415. [CrossRef] [PubMed]

36. Sienski, G.; Narayan, P.; Bonner, J.M.; Kory, N.; Boland, S.; Arczewska, A.A.; Ralvenius, W.T.; Akay, L.; Lockshin, E.; He, L.; et al. APOE4 disrupts intracellular lipid homeostasis in human iPSC-derived glia. Sci. Transl. Med. 2021, 13. [CrossRef]

37. Hu, C.; Chen, C.; Dong, X.P. Impact of COVID-19 Pandemic on Patients With Neurodegenerative Diseases. Front. Aging Neurosci. 2021, 13, 664965. [CrossRef]

38. Kuo, C.L.; Pilling, L.C.; Atkins, J.L.; Masoli, J.A.H.; Delgado, J.; Kuchel, G.A.; Melzer, D. APOE e4 Genotype Predicts Severe COVID-19 in the UK Biobank Community Cohort. J. Gerontol. Ser. A Biol. Sci. Med. Sci. 2020, 75, 2231-2232. [CrossRef]

39. Kurki, S.N.; Kantonen, J.; Kaivola, K.; Hokkanen, L.; Mäyränpää, M.I.; Puttonen, H.; Martola, J.; Pöyhönen, M.; Kero, M.; Tuimala, J.; et al. APOE $\varepsilon 4$ associates with increased risk of severe COVID-19, cerebral microhaemorrhages and post-COVID mental fatigue: A Finnish biobank, autopsy and clinical study. Acta Neuropathol. Commun. 2021, 9, 199. [CrossRef]

40. Ding, Q.; Shults, N.V.; Gychka, S.G.; Harris, B.T.; Suzuki, Y.J. Protein Expression of Angiotensin-Converting Enzyme 2 (ACE2) is Upregulated in Brains with Alzheimer's Disease. Int. J. Mol. Sci. 2021, 22, 1687. [CrossRef]

41. Miners, S.; Kehoe, P.G.; Love, S. Cognitive impact of COVID-19: Looking beyond the short term. Alzheimer's Res. Ther. 2020, 12, 170. [CrossRef]

42. Gibson, S.J.; Voukelatos, X.; Ames, D.; Flicker, L.; Helme, R.D. An examination of pain perception and cerebral event-related potentials following carbon dioxide laser stimulation in patients with Alzheimer's disease and age-matched control volunteers Pain Res. Manag. 2001, 6, 126-132. [CrossRef]

43. Achterberg, W.P.; Pieper, M.J.; van Dalen-Kok, A.H.; de Waal, M.W.; Husebo, B.S.; Lautenbacher, S.; Kunz, M.; Scherder, E.J.; Corbett, A. Pain management in patients with dementia. Clin. Interv. Aging 2013, 8, 1471-1482. [CrossRef]

44. Corbett, A.; Husebo, B.; Malcangio, M.; Staniland, A.; Cohen-Mansfield, J.; Aarsland, D.; Ballard, C. Assessment and treatment of pain in people with dementia. Nat. Rev. Neurol. 2012, 8, 264-274. [CrossRef]

45. Scuteri, D.; Rombolá, L.; Tridico, L.; Mizoguchi, H.; Watanabe, C.; Sakurada, T.; Sakurada, S.; Corasaniti, M.T.; Bagetta, G.; Morrone, L.A. Neuropharmacological Properties of the Essential Oil of Bergamot for the Clinical Management of Pain-Related BPSDs. Curr. Med. Chem. 2019, 26, 3764-3774. [CrossRef]

46. Scuteri, D.; Rombolà, L.; Morrone, L.A.; Bagetta, G.; Sakurada, S.; Sakurada, T.; Tonin, P.; Corasaniti, M.T. Neuropharmacology of the Neuropsychiatric Symptoms of Dementia and Role of Pain: Essential Oil of Bergamot as a Novel Therapeutic Approach. Int. J. Mol. Sci. 2019, 20, 3327. [CrossRef]

47. Schneider, L.S.; Dagerman, K.S.; Insel, P. Risk of death with atypical antipsychotic drug treatment for dementia: Meta-analysis of randomized placebo-controlled trials. JAMA 2005, 294, 1934-1943. [CrossRef]

48. Maust, D.T.; Kim, H.M.; Seyfried, L.S.; Chiang, C.; Kavanagh, J.; Schneider, L.S.; Kales, H.C. Antipsychotics, other psychotropics, and the risk of death in patients with dementia: Number needed to harm. JAMA Psychiatry 2015, 72, 438-445. [CrossRef]

49. Witlox, J.; Eurelings, L.S.M.; de Jonghe, J.F.M.; Kalisvaart, K.J.; Eikelenboom, P.; van Gool, W.A. Delirium in Elderly Patients and the Risk of Postdischarge Mortality, Institutionalization, and Dementia: A Meta-analysis. JAMA 2010, 304, 443-451. [CrossRef]

50. Brown, E.E.; Kumar, S.; Rajji, T.K.; Pollock, B.G.; Mulsant, B.H. Anticipating and Mitigating the Impact of the COVID-19 Pandemic on Alzheimer's Disease and Related Dementias. Am. J. Geriatr. Psychiatry Off. J. Am. Assoc. Geriatr. Psychiatry 2020, $28,712-721$. [CrossRef]

51. Agostini, M.; Moja, L.; Banzi, R.; Pistotti, V.; Tonin, P.; Venneri, A.; Turolla, A. Telerehabilitation and recovery of motor function: A systematic review and meta-analysis. J. Telemed. Telecare 2015, 21, 202-213. [CrossRef]

52. Hadjistavropoulos, T.; Herr, K.; Turk, D.C.; Fine, P.G.; Dworkin, R.H.; Helme, R.; Jackson, K.; Parmelee, P.A.; Rudy, T.E.; Lynn Beattie, B.; et al. An interdisciplinary expert consensus statement on assessment of pain in older persons. Clin. J. Pain 2007, 23, S1-S43. [CrossRef]

53. Husebo, B.S.; Strand, L.I.; Moe-Nilssen, R.; Husebo, S.B.; Ljunggren, A.E. Pain in older persons with severe dementia. Psychometric properties of the Mobilization-Observation-Behaviour-Intensity-Dementia (MOBID-2) Pain Scale in a clinical setting. Scand. J. Caring Sci. 2010, 24, 380-391. [CrossRef]

54. Cipriani, G.; Fiorino, M.D. Access to Care for Dementia Patients Suffering From COVID-19. Am. J. Geriatr. Psychiatry Off. J. Am. Assoc. Geriatr. Psychiatry 2020, 28, 796-797. [CrossRef]

55. Global, regional, and national burden of neurological disorders, 1990-2016: A systematic analysis for the Global Burden of Disease Study 2016. Lancet. Neurol. 2019, 18, 459-480. [CrossRef] 
56. Teipel, S.; Heine, C.; Hein, A.; Krüger, F.; Kutschke, A.; Kernebeck, S.; Halek, M.; Bader, S.; Kirste, T. Multidimensional assessment of challenging behaviors in advanced stages of dementia in nursing homes-The insideDEM framework. Alzheimer's Dement. Amst. Neth. 2017, 8, 36-44. [CrossRef]

57. Carhart-Harris, R.; Giribaldi, B.; Watts, R.; Baker-Jones, M.; Murphy-Beiner, A.; Murphy, R.; Martell, J.; Blemings, A.; Erritzoe, D.; Nutt, D.J. Trial of Psilocybin versus Escitalopram for Depression. N. Engl. J. Med. 2021, 384, 1402-1411. [CrossRef]

58. Scuteri, D.; Crudo, M.; Rombolà, L.; Watanabe, C.; Mizoguchi, H.; Sakurada, S.; Sakurada, T.; Greco, R.; Corasaniti, M.T.; Morrone, L.A.; et al. Antinociceptive effect of inhalation of the essential oil of bergamot in mice. Fitoterapia 2018, 129, 20-24. [CrossRef]

59. Rombolà, L.; Scuteri, D.; Adornetto, A.; Straface, M.; Sakurada, T.; Sakurada, S.; Mizoguchi, H.; Corasaniti, M.T.; Bagetta, G.; Tonin, P.; et al. Anxiolytic-Like Effects of Bergamot Essential Oil Are Insensitive to Flumazenil in Rats. Evid. -Based Complementary Altern. Med. Ecam 2019, 2019, 2156873. [CrossRef]

60. Scuteri, D.; Cassano, R.; Trombino, S.; Russo, R.; Mizoguchi, H.; Watanabe, C.; Hamamura, K.; Katsuyama, S.; Komatsu, T.; Morrone, L.A.; et al. Development and Translation of NanoBEO, a Nanotechnology-Based Delivery System of Bergamot Essential Oil Deprived of Furocumarins, in the Control of Agitation in Severe Dementia. Pharmaceutics 2021, 13, 379. [CrossRef]

61. Scuteri, D.; Sandrini, G.; Tamburin, S.; Corasaniti, M.T.; Nicotera, P.; Tonin, P.; Bagetta, G. Bergamot rehabilitation AgaINst agitation in dementia (BRAINAID): Study protocol for a randomized, double-blind, placebo-controlled trial to assess the efficacy of furocoumarin-free bergamot loaded in a nanotechnology-based delivery system of the essential oil in the treatment of agitation in elderly affected by severe dementia. Phytother. Res. PTR 2021, 35, 5333-5338. [CrossRef] [PubMed]

62. Scuteri, D.; Mantovani, E.; Tamburin, S.; Sandrini, G.; Corasaniti, M.T.; Bagetta, G.; Tonin, P. Opioids in Post-stroke Pain: A Systematic Review and Meta-Analysis. Front. Pharm. 2020, 11, 587050. [CrossRef] [PubMed] 